\title{
Adubação Nitrogenada em Capim-Coastcross: Efeitos na Extração de Nutrientes e Recu- peração Aparente do Nitrogênio ${ }^{1}$
}

\author{
Ana Cândida Primavesi², Odo Primavesi ${ }^{2,5}$, Luciano de Almeida Corrêa ${ }^{2}$, Heitor Cantarella ${ }^{3,5}$, \\ Aliomar Gabriel da Silva ${ }^{2}$, Alfredo Ribeiro de Freitas ${ }^{2}$, Lúcio José Vivaldi ${ }^{4}$
}

\begin{abstract}
RESUMO - Foi conduzido experimento em Latossolo Vermelho Distrófico típico, em São Carlos, SP, para avaliar o efeito de doses e fontes de nitrogênio $(\mathrm{N})$, no teor, extração dos nutrientes e na recuperação do $\mathrm{N}$ aplicado em capim-coastcross (Cynodon dactylon cv. Coastcross). Foram aplicadas sobre a superfície do solo cinco doses de $\mathrm{N}\left(0,25,50,100\right.$ e $\left.200 \mathrm{~kg} \mathrm{ha}^{-1} \mathrm{corte}^{-1}\right)$, na forma de uréia ou de nitrato de amônio, em cinco períodos consecutivos, durante a estação chuvosa. Foram determinados os teores e calculada a extração de nutrientes e a recuperação do N. Houve aumento na extração dos nutrientes com o aumento da produção de forragem, com elevados valores principalmente para N e K. Para altas produções de forragem (tratamento $500 \mathrm{~kg} \mathrm{ha}^{-1} \mathrm{ano}^{-1} \mathrm{de} \mathrm{N}$ ) e para as duas fontes de nitrogênio as extrações dos macronutrientes foram maiores para $\mathrm{K}$ e N, seguidas de $\mathrm{Ca}, \mathrm{S}, \mathrm{P}$ e $\mathrm{Mg}$ e dos micronutrientes $\mathrm{Fe}, \mathrm{Mn}, \mathrm{Zn}$ e Cu. A recuperação média de $\mathrm{N}$ da uréia foi de $68 \%$ do $\mathrm{N}$ obtido do nitrato de amônio, que variou, em média, de 68 a $75 \%$.
\end{abstract}

Palavras-chave: Cynodon dactylon, doses de N, nitrato de amônio, nitrogênio absorvido, produção de biomassa, uréia

\section{Nitrogen Fertilization in Coastcross Grass: Effects on Nutrient Extraction and Apparent Nitrogen Recovery}

\begin{abstract}
Contents, nutrient extraction, and apparent applied N recovery were determined in a coastcross pasture established on a dark red latosol (Hapludox), in São Carlos, SP, Brazil, receiving five rates of $\mathrm{N}$ as urea or amonium nitrate, surface-applied (0, 25, 50,100 , and $200 \mathrm{~kg} \mathrm{ha}^{-1}$ cutting $^{-1}$ ) in five consecutive periods, during the rainy season. Nutrient extraction increased with increasing nitrogen rates. When forage yield was high (treatment with $500 \mathrm{~kg} \mathrm{ha}^{-1} \mathrm{year}^{-1}$ of $\mathrm{N}$ ) and for both fertilizers, macronutrient extraction was greater for $\mathrm{K}$ and $\mathrm{N}$, followed by $\mathrm{Ca}, \mathrm{S}, \mathrm{P}$, and $\mathrm{Mg}$. Micronutrient extraction occurred in the following decreasing order: Fe, Mn, $\mathrm{Zn}$, and $\mathrm{Cu}$. Nitrogen recoveries from urea and ammonium nitrate surface-applied on coastcross pasture were calculated. Significant differences occurred within periods $(\mathrm{P}<0.05)$, depending on climatic conditions. Mean $\mathrm{N}$ recovery of urea was about $68 \%$ of that of ammonium nitrate. Recovery of ammonium nitrate-N ranged from 68 to $75 \%$ of applied $\mathrm{N}$.
\end{abstract}

Key Words: ammonium nitrate, biomass production, Cynodon dactylon, nitrogen levels, nitrogen uptake, urea

\section{Introdução}

As pastagens constituem o principal e mais barato componente da dieta de bovinos e, como tal, representam a base de sustentação da pecuária de corte no Brasil. Todavia, a maioria das pastagens está na região de Cerrados, nas áreas de menor fertilidade, explorada de maneira extrativista e, como conseqüência, em processo de degradação. Essa situação tem contribuído para que a pecuária de corte apresente, há décadas, índices zootécnicos muito baixos (Corsi, 1986), com taxa de lotação das pastagens em torno de 0,5 $\mathrm{UA} \mathrm{ha}^{-1} \mathrm{e}$ produtividade na faixa de $100 \mathrm{~kg} \mathrm{ha}^{-1} \mathrm{ano}^{-1}$ de peso vivo.
Embora as gramíneas forrageiras tropicais não sejam de excelente qualidade, pois o ganho de peso vivo que proporcionam está na faixa de 0,6 a $0,8 \mathrm{~kg}$ animal $^{-1}$ dia $^{-1}$ (Quinn et al., 1962; Gomide et al., 1984), a produção animal por área pode ser muito elevada, com valores acima de $1.200 \mathrm{~kg} \mathrm{ha}^{-1} \mathrm{ano}^{-1} \mathrm{de}$ peso vivo (Corsi, 1986), pelo seu grande potencial de produção de matéria seca.

A adubação em pastagens, principalmente a nitrogenada, está entre os fatores mais importantes a determinar a produção por área. A resposta das gramíneas forrageiras a altas doses de nitrogênio tem sido relatada por vários pesquisadores (VicenteChandler, 1959; Werner et al., 1967; Corsi, 1986).

\footnotetext{
1 Trabalho financiado pelo Convênio Embrapa/Petrobrás.

${ }^{2}$ Pesquisador(a) da Embrapa Pecuária Sudeste, CP 339, CEP: 13560-970 São Carlos, SP. E.mail: anacan@cppse.embrapa.br; odo@cppse.embrapa.br; luciano@cppse.embrapa.br; aliomar@cppse.embrapa.br; alfredo@cppse.embrapa.br

${ }^{3}$ Pesquisador do Instituto Agronômico de Campinas, CP 28, CEP: 13011-970 Campinas, SP. E.mail: cantarella@iac.sp.gov.br

${ }_{4}^{4}$ Professor Universidade de Brasília, Instituto de Ciências Exatas, Caixa Postal 4481, CEP: 70910-900 Brasília, DF. E.mail: vivaldi@unb.br

5 Bolsista do CNPq.
} 
Respostas até $1.800 \mathrm{~kg} \mathrm{ha}^{-1} \mathrm{ano}^{-1}$ de $\mathrm{N}$ foram relatadas por Vicente-Chandler (1959), ocorrendo, de modo geral, os maiores incrementos de produção na faixa de 300 a $400 \mathrm{~kg} \mathrm{ha}^{-1} \mathrm{ano}^{-1}$ de N (Olsen, 1972; Werner et al., 1967; Gomes et al., 1987).

Com a maior produção vegetal, ocorre a extração de outros nutrientes do solo, que, se não repostos, podem limitar a eficiência futura da adubação nitrogenada. Este efeito ocorre também em sistemas de produção de bovinos a pasto, pois, embora ocorra reciclagem local pelos excrementos animais da maior parte dos nutrientes ingeridos (Mott, 1974; Wilkinson \& Lowrey, 1973), e que pode chegar a $90 \%$ para o N (Mott, 1974; Boddey et al., 1996), a distribuição é desuniforme e as perdas de $\mathrm{N}$ podem ser muito importantes (Corsi \& Martha Jr., 1997).

Torna-se, então, necessário maior detalhamento dos conhecimentos sobre a extração de nutrientes pelas forrageiras, especialmente em sistemas intensivos que utilizam elevadas doses de fertilizantes, a fim de orientar adubações futuras e evitar prejuízos devidos a desequilíbrios nutricionais.

A recuperação aparente do $\mathrm{N}$ do fertilizante aplicado em pastagens está dentro dos limites de 50 a $80 \%$ e, com maior freqüência, entre 65 e 70\% (Dilz, 1988; Morisson et al., 1989, citados por Whitehead, 1995). Com aumento das doses de N, menos N é recuperado. De acordo com Corsi (1975), baixa recuperação do $\mathrm{N}$ pelas forrageiras tropicais deveria ser esperada, devido à profundidade dos solos e chuvas fortes em alguns períodos. Todavia, Corsi (1994) relata que mais de $80 \%$ do $\mathrm{N}$ pode ser recuperado, quando o adubo é adequadamente aplicado.

A aplicação superficial da uréia, o mais comum fertilizante nitrogenado no mercado brasileiro, pode reduzir a quantidade de $\mathrm{N}$ recuperado pelas plantas, devido às perdas de $\mathrm{NH}_{3}$ por volatilização (Terman, 1979). A uréia apresenta alta concentração de N, é de fácil manipulação e causa menor acidificação no solo, o que a torna potencialmente superior a outras fontes de $\mathrm{N}$, do ponto de vista econômico. Isto encoraja estudos com uréia, principalmente sobre sua eficácia em pastagens manejadas intensivamente, sob condições climáticas com alto potencial evapotranspirativo.

Foi, então, conduzido este experimento em Latossolo Vermelho Distrófico típico, em São Carlos, SP, para avaliar o efeito de doses e fontes de nitrogênio $(\mathrm{N})$, no teor e na extração dos nutrientes e na recuperação do $\mathrm{N}$ aplicado em capim-coastcross (Cynodon dactylon cv. Coastcross).

\section{Material e Métodos}

O experimento foi realizado, de 06/11/98 a 15/04/99, em pastagem de capim-coastcross (Cynodon dactylon cv. Coastcross) sobre Latossolo Vermelho Distrófico típico, com $30 \%$ de argila, na fazenda Canchim, São Carlos, SP, na latitude $22^{\circ} 01^{\prime}$ S, longitude $47^{\circ} 54^{\prime}$ W e altitude de $836 \mathrm{~m}$, sob clima tropical de altitude. As características químicas do solo, na camada de 0-20 cm, no início do experimento, foram: $\mathrm{pH}$ em $\mathrm{CaCl}_{2}=5,6$, M.O. $=32 \mathrm{~g} \mathrm{dm}^{-3}$, P-resina $=$ $27 \mathrm{mg} \mathrm{dm}^{-3}, \mathrm{~K}=5,1 \mathrm{mmol}_{\mathrm{c}} \mathrm{dm}^{-3}, \mathrm{Ca}=25 \mathrm{mmol}_{\mathrm{c}} \mathrm{dm}^{-3}$, $\mathrm{Mg}=14 \mathrm{mmol}_{\mathrm{c}} \mathrm{dm}^{-3}, \mathrm{CTC}$ a pH $7=65 \mathrm{mmol}_{\mathrm{c}} \mathrm{dm}^{-3}$, $\mathrm{V}=67 \%$. A fertilidade do solo foi corrigida para uma saturação por bases de $70 \%$, além de receber $100 \mathrm{~kg} \mathrm{ha}^{-1}$ de $\mathrm{P}_{2} \mathrm{O}_{5}$ na forma de superfosfato simples e FTE BR12 na dose de $30 \mathrm{~kg} \mathrm{ha}^{-1}$. O K, na forma de $\mathrm{KCl}$, foi aplicado por ocasião das adubações nitrogenadas na dose de $380 \mathrm{~kg} \mathrm{ha}^{-1}$ de $\mathrm{K}_{2} \mathrm{O}$ nos tratamentos 0,125 e $250 \mathrm{~kg} \mathrm{ha}^{-1} \mathrm{ano}^{-1} \mathrm{de} \mathrm{N}$ e na dose de $700 \mathrm{~kg} \mathrm{ha}^{-1} \mathrm{de}$ $\mathrm{K}_{2} \mathrm{O}$ nos tratamentos 500 e $1.000 \mathrm{~kg} \mathrm{ha}^{-1} \mathrm{ano}^{-1}$ de N, com base na extração esperada pelas plantas. $\mathrm{O}$ potássio foi parcelado da seguinte forma: após o corte de uniformização, todas as parcelas receberam $60 \mathrm{~kg} \mathrm{ha}^{-1}$ de $\mathrm{K}_{2} \mathrm{O}$; após o primeiro e o segundo cortes, as parcelas com 0,25 e $50 \mathrm{~kg} \mathrm{ha}^{-1}$ corte $^{-1}$ de $\mathrm{N}$ receberam $60 \mathrm{~kg} \mathrm{ha}^{-1}$ de $\mathrm{K}_{2} \mathrm{O}$ e as com 100 e $200 \mathrm{~kg} \mathrm{ha}^{-1}$ corte $^{-1}$ de N, $120 \mathrm{~kg} \mathrm{ha}^{-1}$ de $\mathrm{K}_{2} \mathrm{O}$; após o terceiro e o quarto cortes, as parcelas com 0,25 e $50 \mathrm{~kg} \mathrm{ha}^{-1}$ corte $^{-1}$ de $\mathrm{N}$ receberam $100 \mathrm{~kg} \mathrm{ha}^{-1} \mathrm{de}_{2} \mathrm{O}$ e as com 100 e $200 \mathrm{~kg} \mathrm{ha}^{-1}$ de $\mathrm{N}_{\text {corte }}^{-1}, 200 \mathrm{~kg} \mathrm{ha}^{-1}$ de $\mathrm{K}_{2} \mathrm{O}$.

$\mathrm{O}$ delineamento experimental foi o de blocos casualizados com nove tratamentos organizados em esquema fatorial $(2 \times 4)+1$ (duas fontes: uréia e nitrato de amônio e cinco doses de N: 0, 25, 50, 100, $200 \mathrm{~kg} \mathrm{ha}^{-1}$ corte $^{-1}$ ) e quatro repetições. Consideraram-se as duas testemunhas (dose 0) como um tratamento (Gates, 1991). O nitrogênio foi aplicado em cinco períodos (após o corte de uniformização e após os demais cortes, até o quarto corte) durante a época das águas. A área das parcelas foi de $4 \times 5 \mathrm{~m}$, com área útil de $6 \mathrm{~m}^{2}$ para avaliação da produção de forragem.

Os cortes foram realizados na altura de $10 \mathrm{~cm} \mathrm{e}$ a intervalos médios de 24 dias semelhantes ao período de descanso utilizado no pastejo rotacionado, anteriormente feito na área. Após a pesagem da matéria fresca, foi separada amostra com $500 \mathrm{~g}$, que foi seca em estufa com circulação forçada de ar, à temperatura de $60^{\circ} \mathrm{C}$, até obter peso constante, para

R. Bras. Zootec., v.33, n.1, p.68-78, 2004 
determinação do teor de água e cálculo do peso da matéria seca. Foi determinado o teor de minerais na matéria seca da forragem (Malavolta et al., 1989) e calculada a extração de cada elemento.

A recuperação aparente do $\mathrm{N}(\mathrm{rec})$, em $\%$, foi calculada pela fórmula: $\mathrm{N}(\mathrm{rec})=100 \times[(\mathrm{N}(\mathrm{extr})$ na parcela fertilizada - N(extr) na parcela testemunha)/ dose de $\mathrm{N}$ aplicada]. A extração de $\mathrm{N}($ extr) foi calculada pela fórmula $\mathrm{N}(\mathrm{extr})=0,001 \mathrm{MS} \times \mathrm{TN}$, em que $\mathrm{N}($ extr $)=\mathrm{N}$ extraído em $\mathrm{kg} \mathrm{ha}^{-1} ; \mathrm{MS}=$ matéria seca em $\mathrm{kg} \mathrm{ha}^{-1} ; \mathrm{TN}=$ teor de $\mathrm{N}$ em $\mathrm{g} \mathrm{kg}{ }^{-1}$. A quantidade de $\mathrm{N}$ na forragem das parcelas não adubadas foi utilizada para estimar o suprimento de $\mathrm{N}$ proveniente do solo e da atmosfera.

Foi realizada a análise de variância, com desdobramento e avaliação do peso das componentes do primeiro ao quarto grau, e utilizando-se o teste F, para comparar as médias das fontes de nitrogênio, bem como ajustadas equações de regressão linear simples e quadrática para as curvas de teores e de extração de nutrientes, em função das doses de nitrogênio aplicadas (SAS, 1993).

\section{Resultados e Discussão}

A análise de variância mostrou, em geral, diferenças $(\mathrm{P}<0,05)$ entre fontes de $\mathrm{N}$ aplicadas e interação doses $\mathrm{x}$ fontes para teores de N, K e Zn (Tabela 1).

Ocorreu interação doses dentro de fontes para N, porque o nitrato de amônio apresentou vantagem significativa como fonte de fornecimento de $\mathrm{N}$, indicada pelo teor absoluto (Tabela 1) e também pelo ponto de máxima, 29\% menor para nitrato de amônio (Tabela 2), porque a uréia perdeu aproximadamente $28 \%$ de $\mathrm{N}$ na forma de amônia (Primavesi et al., 2001).

Para K, a interação é explicada pela potencialização da absorção desse cátion pela absorção de $\mathrm{N}-\mathrm{NO}_{3}$, que parece predominar com a fonte nitrato de amônio (Breteler, 1973), como mostram os valores absolutos e o coeficiente angular da reta $50 \%$ maior para nitrato de amônio (Tabela 2).

A interação para o $\mathrm{Zn}$ pode ser explicada de modo semelhante ao potássio, como indicado pelo coeficiente angular da reta $150 \%$ maior (Tabela 2), ao lado da possibilidade de a maior absorção de $\mathrm{N}$ afetar o balanço hormonal em que o zinco está envolvido (Malavolta, 1980).

Os teores de $\mathrm{N}$ nas plantas aumentaram com o acréscimo das doses de $\mathrm{N}$, de forma quadrática para uréia e nitrato de amônio. Fonseca et al. (1984) verificaram em pastagem de capim-coastcross estabelecida, recebendo doses de 0,100, 200, 300 e $400 \mathrm{~kg} \mathrm{ha}^{-1}$ ano $^{-1}$ de $\mathrm{N}$ aplicadas como uréia, após cada um dos seis cortes do período chuvoso, que houve aumento no teor de $\mathrm{N}$ nas plantas até a dose de $300 \mathrm{~kg} \mathrm{ha}^{-1} \mathrm{ano}^{-1}$. Almeida \& Monteiro (1995) também verificaram correlação direta do teor de $\mathrm{N}$ foliar de capim-coastcross com as doses de nitrogênio na solução nutritiva.

Coto et al. (1990) testaram capim-coastcross, recebendo doses de 0,200 e $400 \mathrm{~kg} \mathrm{ha}^{-1} \mathrm{ano}^{-1}$ de $\mathrm{N}$, irrigação na seca e cortado a cada 35 dias, além de $50 \mathrm{~kg} \mathrm{ha}^{-1}$ de $\mathrm{P}_{2} \mathrm{O}_{5}$ e $100 \mathrm{~kg} \mathrm{ha}^{-1}$ de $\mathrm{K}_{2} \mathrm{O}$ no início de cada estação. Os autores verificaram aumento no teor de $\mathrm{N}$ total na parte aérea das plantas, com as doses crescentes de N. Com a dose de $400 \mathrm{~kg} \mathrm{ha}^{-1}$ ano ${ }^{-1}$ de $\mathrm{N}$, obtiveram teores de $18,2 \mathrm{~g} \mathrm{~kg}^{-1}$ de $\mathrm{N}$ na forragem, na estação seca, sendo que no presente trabalho esses teores foram alcançados com a dose de $5 \times 50 \mathrm{~kg} \mathrm{ha}^{-1} \mathrm{ano}^{-1}$ de $\mathrm{N}$, na forma de uréia, e de $5 \times 25 \mathrm{~kg} \mathrm{ha}^{-1} \mathrm{ano}^{-1}$ de $\mathrm{N}$, na forma de nitrato de amônio. Provavelmente, a maior absorção de $\mathrm{N}$ no presente trabalho seja decorrente da maior quantidade de potássio aplicada (Usherwood, 1982) e do menor intervalo de cortes (24 dias).

Brunet et al. (1988a) verificaram aumentos no teor de $\mathrm{N}$ na forragem de capim-coastcross com a adubação nitrogenada, e que na época seca os teores eram mais elevados, ao redor de $11,6 \mathrm{~g} \mathrm{~kg}^{-1}$. Ainda assim esses teores foram menores que os encontrados no presente trabalho, na época das chuvas, nas plantas do tratamento que não recebeu nitrogênio, que foi de 16,5 $\mathrm{g} \mathrm{kg}^{-1}$ (Tabela 1).

Coutinho et al. (2001) trabalharam com pastagem irrigada de capim-coastcross, aplicando doses de 30 , $60,120,180$ e $240 \mathrm{~kg} \mathrm{ha}^{-1}$ corte $^{-1}$ de N (nitrato de amônio) e de 30,60, 120 e $180 \mathrm{~kg} \mathrm{ha}^{-1}$ corte $^{-1}$ de $\mathrm{K}$ (cloreto de potássio). Em 12 cortes, verificaram que a adição de $\mathrm{N}$ e de $\mathrm{K}$ aumentou significativamente os teores desses nutrientes na parte aérea das plantas. Observaram sintomas típicos de deficiência desses dois nutrientes nas plantas dos tratamentos que receberam as menores doses de $\mathrm{N}$ e de $\mathrm{K}\left(30 \mathrm{~kg} \mathrm{ha}^{-1}\right.$ corte $\left.^{-1}\right)$, associados às concentrações menores que 13,0 e 9,0 $\mathrm{g} \mathrm{kg}^{-1}$, respectivamente, de $\mathrm{N}$ e K. No presente trabalho, a dose de $25 \mathrm{~kg} \mathrm{ha}^{-1}$ corte $^{-1}$ de N, aplicada na forma de nitrato de amônio, resultou em teores maiores de $\mathrm{N}$ na planta, não sendo observados sintomas de deficiência, mas a dose de $\mathrm{K}$ aplicada também foi maior por corte, refletindo em teores 
maiores de $\mathrm{K}$ na planta e, possivelmente, em melhor absorção do N pelas plantas (Usherwood, 1982).

Neste trabalho, os teores de $\mathrm{P}$ reduziram de forma linear com as doses de N, para ambos os fertilizantes (Tabelas 1 e 2), concordando com os dados obtidos por Fonseca et al. (1984). Essa redução nos teores de $\mathrm{P}$ pode ser explicada em parte pelo efeito de diluição, mas, mesmo assim, permaneceram elevados em todos os tratamentos. Para o milho, verificou-se que o incremento das doses de $\mathrm{N}$ causou aumento progressivo na utilização do fertilizante fosfatado (Arnon, 1975). A aplicação de $\mathrm{N}$ aumenta a absorção de $\mathrm{P}$ mais rapidamente do que a produção de matéria seca, de tal forma que a concentração de

Tabela 1 - Teores de nutrientes na forragem de capim-coastcross, em função de fontes e doses de nitrogênio (média de cinco cortes)

Table 1 - Nutrient content in coastcross grass forage, as function of sources and rates of nitrogen (means of five cuttings)

Doses de $\mathrm{N} \quad$ Nutrientes

$N$ rates Nutrients

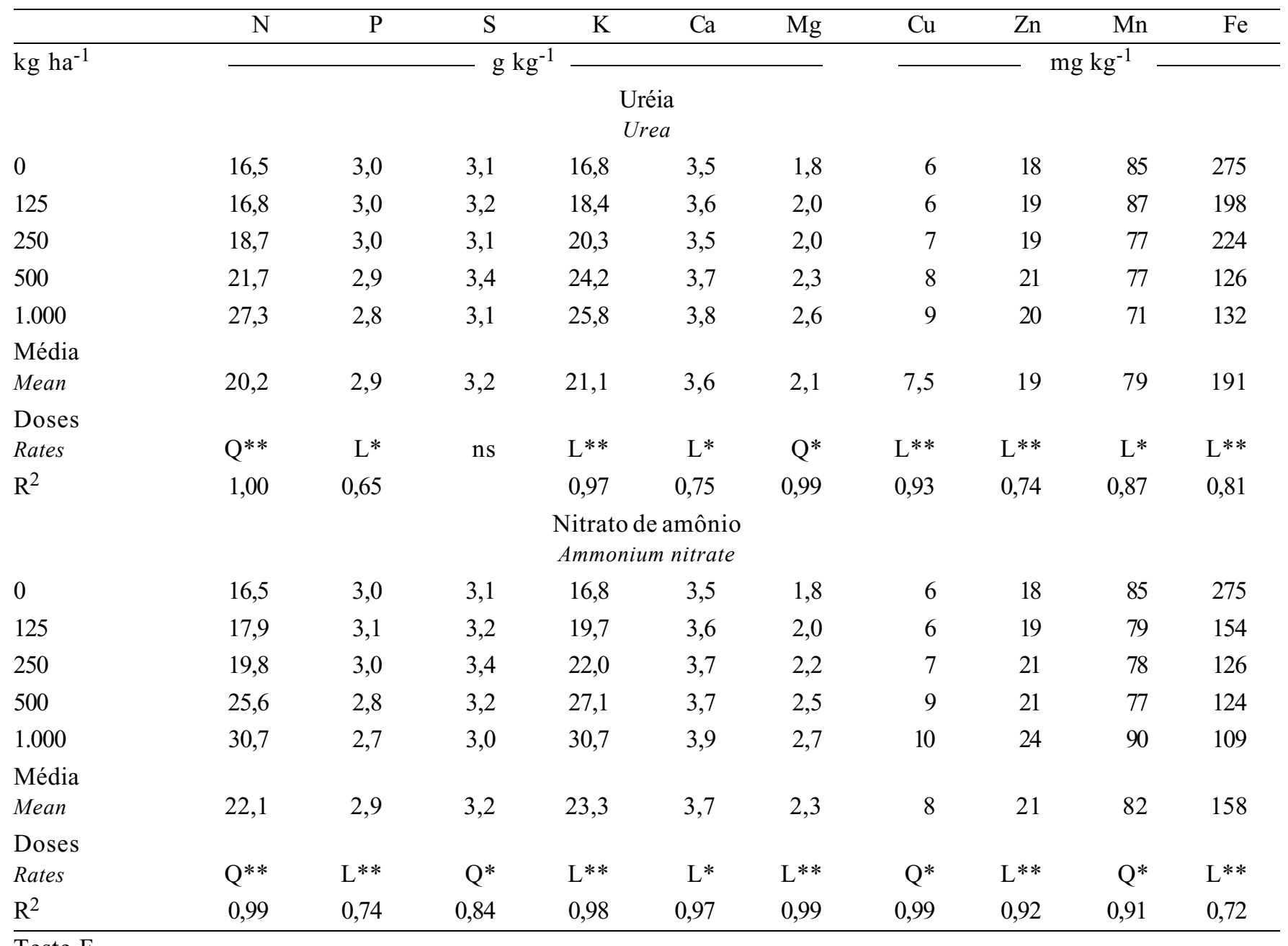

Teste $\mathrm{F}$

$F$ test

Adubos

Fertilizers

Ad.x doses

Fert. $x$ rates

\begin{tabular}{|c|c|c|c|c|c|c|c|c|c|}
\hline$* *$ & $\mathrm{~ns}$ & $\mathrm{~ns}$ & $* *$ & $\mathrm{~ns}$ & $* *$ & $* *$ & $* *$ & $\mathrm{~ns}$ & $\mathrm{~ns}$ \\
\hline$* *$ & $\mathrm{~ns}$ & $\mathrm{~ns}$ & $*$ & $\mathrm{~ns}$ & $\mathrm{~ns}$ & $\mathrm{~ns}$ & $* *$ & $\mathrm{~ns}$ & $\mathrm{~ns}$ \\
\hline
\end{tabular}


$\mathrm{P}$ nas plantas aumenta. De acordo com este mesmo autor, a influência do $\mathrm{N}$ na disponibilidade do $\mathrm{P}$ difere com a forma na qual o $\mathrm{N}$ é aplicado e com as condições do solo. Geralmente, ${\mathrm{N}-\mathrm{NH}_{4}}^{+}$aumenta a

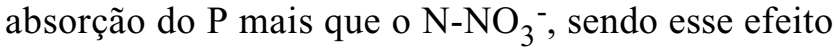
mais pronunciado quando a temperatura do solo aumenta. Fernandes \& Rossielo (1986) relataram que, em Brachiaria decumbens, a concentração de $\mathrm{P}$ na parte aérea das plantas foi menor quando elas

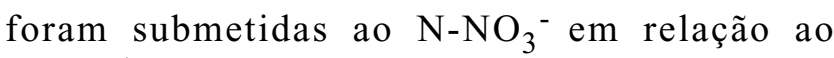
$\mathrm{N}-\mathrm{NH}_{4}{ }^{+}$. No presente experimento, não houve diferença dos adubos na absorção do fósforo (Tabela 1).

Os teores de $\mathrm{Ca}$ cresceram de forma linear com as doses de $\mathrm{N}$ para os dois adubos (Tabela 1). Miller (1999) relata que, em cultivares de grama-bermuda, o aumento das doses de $\mathrm{K}$ resultou em decréscimo dos teores foliares de $\mathrm{Ca}$ e $\mathrm{Mg}$. Neste experimento, onde as quantidades de $\mathrm{K}$ aplicadas foram maiores nas parcelas que receberam as doses de 100 e $200 \mathrm{~kg}$ ha $^{-1}$ corte $^{-1}$ de $\mathrm{N}$, não foi observado decréscimo nos teores de $\mathrm{Ca}$ e de $\mathrm{Mg}$.

Fonseca et al. (1984) obtiveram comportamento variável dos teores de $\mathrm{K}$ com os níveis de aplicação de N. Estudos indicam que níveis e fontes de nitrogênio influenciam a relação do $\mathrm{K}$ com $\mathrm{N}, \mathrm{Ca}$ e $\mathrm{Mg}$ (Usherwood, 1982). Esse mesmo autor relata que Coic \& Lesaint (1971) evidenciaram grande diferença nos teores de cátions nas culturas onde os nitratos estão envolvidos, devido, em parte, ao lugar onde se dá a redução do nitrato. Quando a redução do nitrato ocorre nas folhas, eles sugerem que os cátions são transportados em concentrações equivalentes à dos ânions, tais como o nitrato e, portanto, o transporte de ânion-cátion para as folhas não é específico para $\mathrm{Ca}$, $\mathrm{Mg}$ ou K. Quando a redução do nitrato ocorre nas raízes, resulta na translocação de compostos orgânicos de N, os quais, segundo estes autores, mostram alguma seletividade para $\mathrm{K}$, mais do que para $\mathrm{Ca}$ ou $\mathrm{Mg}$. No presente trabalho, o aumento da absorção de $\mathrm{K}$ e também de $\mathrm{Ca}$ e $\mathrm{Mg}$ (Tabela 1) sugere que o Nnitrato estava predominantemente envolvido, independentemente da fonte nitrogenada, com redução nas raízes.

Werner et al. (1996) apresentam as faixas de teores adequados de nutrientes nas plantas de capimcoastcross, em $\mathrm{g} \mathrm{kg}^{-1}: \mathrm{N}=15$ a $25, \mathrm{P}=1,5$ a 3,0 , $\mathrm{K}=15$ a $30, \mathrm{Ca}=3$ a $8, \mathrm{Mg}=2$ a 4 e $\mathrm{S}=1$ a 3 ; e em $\mathrm{mg} \mathrm{kg}^{-1}: \mathrm{B}=10$ a $25, \mathrm{Cu}=4$ a $14, \mathrm{Zn}=30$ a 50 , $\mathrm{Mn}=40$ a 200 e $\mathrm{Fe}=50$ a 200 . No presente trabalho (Tabela 1), os teores obtidos estão dentro da faixa adequada, com exceção do $\mathrm{Zn}$, que está abaixo. $\mathrm{Na}$ dose de $200 \mathrm{~kg} \mathrm{ha}^{-1}$ corte $^{-1}$ de $\mathrm{N}$, o teor de nitrogênio mostrou-se mais elevado que a faixa considerada adequada, confirmando a observação de acúmulo de N-nitrato na forragem (Primavesi et al., 2001).

Os teores de $\mathrm{Zn}$ aumentaram e os de Fe reduzi-

Tabela 2 - Equações de ajuste para teores de nutrientes na matéria seca de capim-coastcross submetido a fontes e doses de $\mathrm{N}$

Table 2 - Equations of the adjusted curves for mineral content in coastcross grass dry matter submitted to sources and rates of $N$

\begin{tabular}{|c|c|c|c|c|}
\hline & $\begin{array}{l}\text { Uréia } \\
\text { Urea }\end{array}$ & $\mathrm{R}^{2}$ & $\begin{array}{l}\text { Nitrato de amônio } \\
\text { Ammonium nitrate }\end{array}$ & $\mathrm{R}^{2}$ \\
\hline $\mathrm{N}$ & $16,227+0,0469 \mathrm{~N}-0,0000447 \mathrm{~N}^{2}$ & $1,00 * *$ & $16,088+0,0977 \mathrm{~N}-0,0001198 \mathrm{~N}^{2}$ & $0,99 * *$ \\
\hline $\mathrm{P}$ & $2,986-0,00104 \mathrm{~N}$ & $0,65 *$ & $3,005-0,000447 \mathrm{~N}$ & $0,74 * *$ \\
\hline S & $\mathrm{ns}$ & $\mathrm{ns}$ & $3,164+0,00265 \mathrm{~N}-0,0000195 \mathrm{~N}^{2}$ & $0,84^{*}$ \\
\hline $\mathrm{K}$ & $17,402+0,0477 \mathrm{~N}$ & $0,97 * *$ & $17,712+0,0715 \mathrm{~N}$ & $0,98 * *$ \\
\hline $\mathrm{Ca}$ & $3,48+0,00177 \mathrm{~N}$ & $0,75^{*}$ & $3,53+0,00193 \mathrm{~N}$ & $0,97 *$ \\
\hline $\mathrm{Mg}$ & $1,831+0,005 \mathrm{~N}-0,0000065 \mathrm{~N}^{2}$ & $0,99 *$ & $1,902+0,0046 \mathrm{~N}$ & $0,99 * *$ \\
\hline $\mathrm{Cu}$ & $6,37+0,01446 \mathrm{~N}$ & $0,94 * *$ & $6,18+0,0296 \mathrm{~N}-0,0000513 \mathrm{~N}^{2}$ & $0,99 *$ \\
\hline $\mathrm{Zn}$ & $18,261+0,0118 \mathrm{~N}$ & $0,73 * *$ & $18,314+0,0292 \mathrm{~N}$ & $0,91 * *$ \\
\hline $\mathrm{Mn}$ & $84,885-0,0723 \mathrm{~N}$ & $0,87 *$ & $84,54-0,1885 \mathrm{~N}+0,00108 \mathrm{~N}^{2}$ & $0,91 *$ \\
\hline $\mathrm{Fe}$ & $250,55-0,731 \mathrm{~N}$ & $0,81 * *$ & $223,67-0,744 \mathrm{~N}$ & $0,72 * *$ \\
\hline
\end{tabular}

Teor de $\mathrm{N}, \mathrm{P}, \mathrm{K}, \mathrm{Ca}, \mathrm{Mg}, \mathrm{S}$, em $\mathrm{g} \mathrm{kg}^{-1}$ e de $\mathrm{Cu}, \mathrm{Zn}, \mathrm{Mn}, \mathrm{Fe}$, em $\mathrm{mg} \mathrm{kg}^{-1}$.

* ou ** $=$ significância do teste $\mathrm{F}$ no nível de 5 e $1 \%$.

Content of $\mathrm{N}, \mathrm{P}, \mathrm{K}, \mathrm{Ca}, \mathrm{Mg}, \mathrm{S}$, in $\mathrm{g} \mathrm{kg}^{-1}$ and of $\mathrm{Cu}, \mathrm{Zn}, \mathrm{Mn}$ and $\mathrm{Fe}$, in $\mathrm{mg} \mathrm{kg}^{-1}$

${ }^{*}$ or ${ }^{* *}=$ significance of F-test at the level of 5 and $1 \%$. 
ram de forma linear com as doses de N. Os teores de $\mathrm{Cu}$ aumentaram de forma linear com uréia e quadrática com nitrato de amônio. Para uréia verificou-se redução linear dos teores de $\mathrm{Mn}$ com as doses de $\mathrm{N}$ e, para o nitrato de amônio, resposta quadrática, devido ao aumento inexplicável dos teores na dose maior de N (Tabela 1). Coutinho et al. (2001) verificaram que a adubação nitrogenada aumentou os teores de $\mathrm{Mn}$ na parte aérea das plantas, o que não ocorreu no presente experimento.

A análise de variância (Tabela 3 ) mostrou diferenças $(\mathrm{P}<0,05)$ entre adubos para a extração de todos os nutrientes, exceto para o ferro. Ocorreu interação doses dentro de fontes, para $\mathrm{N}$, sendo que o nitrato de amônio apresentou vantagem significativa como fonte de fornecimento de $\mathrm{N}$, indicado pelo teor absoluto (Tabela 1) e também pelo ponto de máxima $55 \%$ menor para nitrato de amônio (Tabela 4), não somente porque a uréia chega a perder aproximadamente $28 \%$ de nitrogênio na forma de amônia (Primavesi et al., 2001), mas também porque a produção de matéria seca foi $27 \%$ superior com nitrato de amônio (Tabela 3).

A extração dos nutrientes ocorreu de forma quadrática para $\mathrm{N}$, estando a maior extração além ou em torno da dose máxima aplicada de $\mathrm{N}$, respectivamente, para uréia e nitrato de amônio (Tabela 3), explicado pela interação doses $\mathrm{x}$ fontes. Essa interação também ocorreu para a extração de $\mathrm{K}, \mathrm{Cu}$ e $\mathrm{Zn}$.

Para K, a interação é explicada pela potencialização da absorção de $\mathrm{N}-\mathrm{NO}_{3}$, que parece predominar com a fonte nitrato de amônio (Breteler, 1973), como mostram os valores absolutos e o coeficiente angular da reta $35 \%$ maior para nitrato de amônio (Tabela 4). A interação para o Zn deve seguir o mesmo raciocínio, como indicado pelo coeficiente angular da reta $33 \%$ maior (Tabela 4 ).

A interação para cobre é devida a sua grande participação no metabolismo do N (Malavolta, 1980), que, por ser maior para nitrato de amônio, com coeficiente angular da reta $28 \%$ superior (Tabela 4 ), leva a sua maior absorção total, em relação à uréia, bem como à maior produção de matéria seca total.

Comparando a extração de nutrientes nas doses de $\mathrm{N}$ mais utilizadas na prática $\left(5 \times 50\right.$ e $\left.5 \times 100 \mathrm{~kg} \mathrm{ha}^{-1} \mathrm{ano}^{-1}\right)$, em relação à testemunha (Tabela 3 ), verificou-se aumento de 3,5 a 5,5 vezes para $\mathrm{Ne} \mathrm{Cu}, 3,0$ a 3,5 vezes para $\mathrm{P}$ e $\mathrm{Mn}, 3$ a 4 vezes para $\mathrm{Se} \mathrm{Ca}, 4,0$ a 6,0 vezes para $\mathrm{K}, 3,0$ a 4,5 vezes para $Z n$ e 2 vezes para $F e$.

Maraschin (1988) relata que a retirada de nutrien- tes do solo pelos cultivares de Cynodon tende a ser elevada com altos rendimentos de forragem e, com o aporte de $\mathrm{N}$, aumenta a produção de matéria seca (MS), exigindo maiores doses de adubos. Esse mesmo autor, citando Pratt \& Darst (1987), apresenta dados que mostram a necessidade de maior disponibilidade de nutrientes para atender a demanda para altas produções e a continuidade das aplicações para níveis sustentáveis de produtividade. Relatam, para a cv. Coastal bermuda, a remoção de nutrientes $\left(\mathrm{kg} \mathrm{ha}^{-1}\right)$ para uma produção de 6 e $12 \mathrm{tha}^{-1}$ de MS, respectivamente, de $\mathrm{N}=270$ e $540, \mathrm{P}=30$ e $61, \mathrm{~K}=250$ e 498, $\mathrm{S}=30$ e $60, \mathrm{Mg}=48$ e 96 . Neste experimento, os dados (Tabela 3 ) também indicam que a extração dos nutrientes aumenta com o aumento da produção de forragem e que essa remoção de nutrientes é elevada.

Verifica-se (Tabela 3) que, nos tratamentos de $5 \times 100$ e $5 \times 200 \mathrm{~kg} \mathrm{ha}^{-1}$ ano $^{-1}$ de N, a maior extração de potássio reflete a maior quantidade desse nutriente aplicada a partir do segundo corte. Como houve redução do incremento de produção de forragem com o aumento das doses de $\mathrm{N}$, principalmente para o nitrato de amônio (Corrêa et al., 2001), esta maior extração de $\mathrm{K}$ nos tratamentos de 5 x 100 e 5 x $200 \mathrm{~kg} \mathrm{ha}^{-1} \mathrm{ano}^{-1}$ de $\mathrm{N}$ sinaliza para o início de um consumo de luxo deste nutriente. Mesa et al. (1989) concluíram que a grama-bermuda-68 apresentou consumo de luxo de $\mathrm{K}$, com nível crítico de $36,4 \mathrm{~g} \mathrm{~kg}^{-1}$ para esse nutriente.

Verifica-se também na Tabela 3, nos tratamentos de $5 \times 100$ e $5 \times 200 \mathrm{~kg} \mathrm{ha}^{-1}$ ano $^{-1}$ de N, que a extração de $\mathrm{N}$ também foi grande. Primavesi et al. (2001) observaram aumento nos teores de N-nitrato $\left(\mathrm{N}^{-\mathrm{NO}_{3}}{ }^{-}\right)$na planta, com aumento das doses de $\mathrm{N}$ para as duas fontes, verificando maior acúmulo de $\mathrm{N}$ nitrato para o nitrato de amônio. Como o nitrato é a forma inorgânica de $\mathrm{N}$ que se acumula na planta, quando o suprimento de $\mathrm{N}$ excede o requerimento para o crescimento, considerando o balanço mineral ocorrente, verificou-se que, nos tratamentos com $5 \mathrm{x}$ $200 \mathrm{~kg} \mathrm{ha}^{-1}$ ano $^{-1}$ de N, onde a resposta em produção foi mais reduzida (Corrêa et al., 2001), o teor de Nnitrato foi significativamente maior $\left(486 \mathrm{mg} \mathrm{kg}^{-1} \mathrm{e}\right.$ $720 \mathrm{mg} \mathrm{kg}^{-1}$, para uréia e nitrato de amônio, respectivamente), indicando que já não compensa mais adubar com N. Isto porque, apesar de o teor deste elemento ter aumentado na planta (Tabela 1), o teor de N-nitrato já estava acumulando na planta, embora ainda estivesse na faixa de segurança para alimentação animal (Whitehead, 1995). Este acúmulo 
de $\mathrm{N}$ na forma de nitrato na planta poderia explicar porque não se observou o efeito de diluição para os teores de $\mathrm{N}$, que continuaram aumentando (Tabela 1) com a maior produção de matéria seca (Tabela 3).

Para altas produções de forragem (tratamento 5 x $100 \mathrm{~kg} \mathrm{ha}^{-1} \mathrm{ano}^{-1}$ de N), considerando os dois adubos, as extrações dos macronutrientes foram maiores para K e N, seguidas de Ca, S, P e Mg e dos micro $\mathrm{Fe}, \mathrm{Mn}, \mathrm{Zn}$ e $\mathrm{Cu}$. Este fato concorda com a afirmação (Silva, 1995) de que os teores de $\mathrm{N}$ disponível no solo são geralmente baixos e que esse elemento exerce papel fundamental na modulação das resposta às adubações de forrageiras.

$\mathrm{Na}$ Tabela 4, são apresentadas as equações de regressão de segundo grau que descrevem as curvas de extração de minerais, entre as quais se destacam

Tabela 3 - Produção de matéria seca (MS) e extração mineral pelo capim-coastcross, em função de fontes e doses de $\mathrm{N}$ (total de cinco cortes)

Table 3 - Dry matter yield (DM) and mineral extraction by coastcross grass, as function of sources and rates of $N$ (total of five cuttings)

\begin{tabular}{|c|c|c|c|c|c|c|c|c|c|c|c|}
\hline $\begin{array}{l}\text { Doses } \mathrm{N} \\
N \text { rates }\end{array}$ & $\begin{array}{l}\mathrm{MS} \\
D M\end{array}$ & $\mathrm{~N}$ & $\mathrm{P}$ & $\mathrm{S}$ & $\mathrm{K}$ & $\mathrm{Ca}$ & $\mathrm{Mg}$ & $\mathrm{Cu}$ & $\mathrm{Zn}$ & $\mathrm{Mn}$ & $\mathrm{Fe}$ \\
\hline $\mathrm{kg} \mathrm{ha}^{-1}$ & 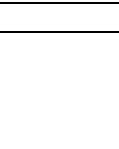 & 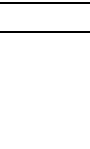 & $-\mathrm{kg}$ & 1 & $\begin{array}{l}\text { Uréia } \\
\text { Urea }\end{array}$ & & 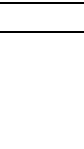 & 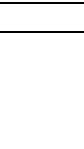 & $-\mathrm{g}$ & & \\
\hline 0 & 4.051 & 69 & 13 & 13 & 64 & 15 & 8 & 24 & 73 & 355 & 798 \\
\hline 125 & 7.153 & 127 & 22 & 24 & 133 & 27 & 15 & 45 & 135 & 621 & 962 \\
\hline 250 & 10.882 & 204 & 33 & 34 & 213 & 38 & 23 & 77 & 207 & 818 & 1523 \\
\hline 500 & 14.428 & 319 & 42 & 49 & 341 & 54 & 34 & 123 & 305 & 1121 & 1510 \\
\hline 1.000 & 17.240 & 475 & 46 & 52 & 436 & 67 & 46 & 152 & 345 & 1195 & 1785 \\
\hline $\begin{array}{l}\text { Média } \\
\text { Mean }\end{array}$ & 10.751 & 239 & 31 & 34 & 237 & 40 & 25 & 84 & 213 & 822 & 1311 \\
\hline $\begin{array}{l}\text { Doses } \\
\text { Rates }\end{array}$ & $\mathrm{L}^{* *}$ & $\mathrm{Q}^{* *}$ & $\mathrm{~L}^{* *}$ & $\mathrm{~L}^{* *}$ & $\mathrm{~L}^{*}$ & $\mathrm{~L}^{* *}$ & $\mathrm{Q}^{*}$ & $\mathrm{~L}^{* *}$ & $\mathrm{~L}^{* *}$ & $\mathrm{~L}^{* *}$ & $\mathrm{~L}^{* *}$ \\
\hline \multicolumn{12}{|c|}{$\begin{array}{l}\text { Nitrato de amônio } \\
\text { Ammonium nitrate }\end{array}$} \\
\hline 0 & 4.051 & 69 & 13 & 13 & 64 & 15 & 8 & 24 & 73 & 355 & 798 \\
\hline 125 & 8.909 & 161 & 28 & 30 & 176 & 33 & 18 & 57 & 172 & 682 & 928 \\
\hline 250 & 13.387 & 270 & 40 & 47 & 289 & 52 & 31 & 100 & 287 & 1044 & 1228 \\
\hline 500 & 17.503 & 446 & 48 & 56 & 467 & 66 & 45 & 152 & 361 & 1362 & 1951 \\
\hline 1.000 & 18.884 & 574 & 51 & 55 & 570 & 73 & 51 & 188 & 449 & 1686 & 2111 \\
\hline $\begin{array}{l}\text { Média } \\
\text { Mean }\end{array}$ & 12.547 & 304 & 36 & 40 & 313 & 48 & 31 & 104 & 268 & 1026 & 1403 \\
\hline $\begin{array}{l}\text { Doses } \\
\text { Rates }\end{array}$ & $\mathrm{Q}^{* *}$ & $\mathrm{Q}^{* *}$ & $\mathrm{Q}^{* *}$ & $\mathrm{Q}^{* *}$ & $\mathrm{~L}^{* *}$ & $\mathrm{Q}^{* *}$ & $\mathrm{~L}^{* *}$ & $\mathrm{~L}^{* *}$ & $\mathrm{~L}^{* *}$ & $\mathrm{~L} * *$ & $\mathrm{~L} * *$ \\
\hline $\mathrm{R}^{2}$ & 0,97 & 0,99 & 1,00 & 0,99 & 0,99 & 0,97 & 0,99 & 0,99 & 0,99 & 0,98 & 0,94 \\
\hline
\end{tabular}

\section{Teste F}

F test

Adubos

Fertilizers

Ad.x doses

Fert. $x$ rate ${ }^{*}$ ou ${ }^{* *}=$ significância do teste $F$ em nível de 5 e $1 \%$. Para doses, apresentada a curva de melhor ajuste (L $=$ Linear simples ou
$Q=$ Quadrática) e o valor do $\mathrm{R}^{2}$.
${ }^{*}$ or $^{* *}=$ significance of F-test at the level of 5 and $1 \%$. For rates, it showed the best adjusted curve type $\left(L=L\right.$ inear or $Q=Q$ Quadratic) with the $R^{2}$ value. 
os coeficientes da componente linear para $\mathrm{N}$ e $\mathrm{K}$ entre fontes.

A recuperação aparente do $\mathrm{N}$ do adubo variou $(\mathrm{P}<0,01)$ com as fontes de $\mathrm{N}$ (Tabela 5). As equações que melhor ajustaram foram as de primeiro grau, sendo a recuperação de $\mathrm{N}$ da uréia explicada pela reta $\mathrm{Y}=51,13-0,0661 \mathrm{~N}$ e a do nitrato de amônio, pela reta $\mathrm{Y}=79,8-0,1614 \mathrm{~N}$.

Com o aumento das doses de N, ocorreu decréscimo na recuperação aparente do $\mathrm{N}$, maior para o nitrato de amônio, devido à redução da eficiência da produção da matéria seca (Primavesi et al., 2000). Brunet et al. (1998b) observaram, para capim-coastcross, decréscimos na porcentagem de recuperação do $\mathrm{N}$, à medida que se aumentou o $\mathrm{N}$ na adubação, passando de $45 \%$, na dose de $80 \mathrm{~kg} \mathrm{ha}^{-1}$ ano $^{-1}$ de N, para $30 \%$, na dose de $240 \mathrm{~kg} \mathrm{ha}^{-1} \mathrm{ano}^{-1}$ de N. Fernandez et al. (1986) estudaram capimcoastcross recém-estabelecido recebendo doses de $0,225,450,675$ e $810 \mathrm{~kg} \mathrm{ha}^{-1} \mathrm{ano}^{-1} \mathrm{de} \mathrm{N}$, aplicadas em quantidades iguais em cada um dos nove cortes anuais, e obtiveram $78 \%$ de recuperação do $\mathrm{N}$ na dose de $225 \mathrm{~kg} \mathrm{ha}^{-1} \mathrm{ano}^{-1}$ e de $60 \%$ na dose de $450 \mathrm{~kg} \mathrm{ha}^{-1} \mathrm{ano}^{-1}$.

Considerando os períodos do segundo ao quinto corte, a recuperação de $\mathrm{N}$ de ambos os fertilizantes foi relativamente elevada para as doses mais usadas em sistemas intensivos de produção $\left(50\right.$ e $100 \mathrm{~kg} \mathrm{ha}^{-1}$ corte $^{-1}$ de N), sendo maior para o nitrato de amônio. A recuperação média de $\mathrm{N}$-uréia foi de $68 \%$ do obtido do nitrato de amônio, que variou, em média, de 68 a $75 \%$ (Tabela 5). Os dados obtidos neste trabalho mostram o alto potencial de extração de $\mathrm{N}$ pelas plantas, considerando que parte do N, não determinado, foi também acumulado pelas raízes e estolões e pela biomassa microbiana, principalmente em sistemas intensivos de utilização das forrageiras. Impithuksa \& Blue (1985), citados por Monteiro (1998), trabalhando com capim-estrela adubado com nitrato de amônio, obtiveram recuperação de $70 \%$ do $\mathrm{N}$ aplicado, sendo $13 \%$ de $\mathrm{N}$ recuperado pelas raízes e estolões, $22 \%$ pela biomassa microbiana do solo e $35 \%$ pela forragem. Esta alta extração de $\mathrm{N}$ pelas gramíneas tropicais contribui para redução de riscos ambientais, tais como as perdas de nitrato, principalmente em solos tropicais profundos.

Considerando os resultados obtidos neste trabalho, para capim-coastcross, em solo com $30 \%$ de argila, e níveis de fertilidade de média a alta para $\mathrm{P}$, $\mathrm{K}$, $\mathrm{Ca}$ e $\mathrm{Mg}$, podem-se recomendar adubações nitrogenadas de 50 e 50 a $100 \mathrm{~kg}^{-1} \mathrm{ha}^{-1}$ corte $^{-1}$, respectivamente, para nitrato de amônio e uréia, para ocorrer a melhor recuperação do $\mathrm{N}$ aplicado. As recomendações de adubação de $\mathrm{N}$ para o Estado de

Tabela 4 - Equações de ajuste para as curvas de extração de minerais por capim-coastcross submetido a fontes e doses de $\mathrm{N}$

Table 4 - Equations of the adjusted curves for mineral extraction by coastcross grass submitted to sources and rates of $N$

\begin{tabular}{lllll} 
& \multicolumn{1}{c}{ Uréia } & \multicolumn{1}{c}{$\mathrm{R}^{2}$} & \multicolumn{1}{c}{$\begin{array}{c}\text { Nitrato de amônio } \\
\text { Ammonium nitrate }\end{array}$} & $\mathrm{R}^{2}$ \\
\hline $\mathrm{N}$ & $66,24+2,944 \mathrm{~N}-0,004481 \mathrm{~N}^{2}$ & $1,00^{* *}$ & $62,512+4,865 \mathrm{~N}-0,01149 \mathrm{~N}^{2}$ & $0,99^{* *}$ \\
$\mathrm{P}$ & $17,37+0,172 \mathrm{~N}$ & $0,98^{* *}$ & $13,836+0,555 \mathrm{~N}-0,00186 \mathrm{~N}^{2}$ & $1,00^{* *}$ \\
$\mathrm{~S}$ & $18,247+0,203 \mathrm{~N}$ & $0,97^{* *}$ & $14,08+0,701 \mathrm{~N}-0,00248 \mathrm{~N}^{2}$ & $0,99^{* *}$ \\
$\mathrm{~K}$ & $88,259+1,925 \mathrm{~N}$ & $0,99^{*}$ & $108,42+2,61 \mathrm{~N}$ & $0,99^{* *}$ \\
$\mathrm{Ca}$ & $19,319+0,265 \mathrm{~N}$ & $0,99^{* *}$ & $15,2+0,784 \mathrm{~N}-0,00248 \mathrm{~N}^{2}$ & $0,97^{* *}$ \\
$\mathrm{Mg}$ & $7,677+0,3337 \mathrm{~N}-0,000716 \mathrm{~N}^{2}$ & $0,99^{*}$ & $12,857+0,225 \mathrm{~N}$ & $0,99^{* *}$ \\
$\mathrm{Cu}$ & $32,576+0,665 \mathrm{~N}$ & $0,99^{* *}$ & $37,868+0,8477 \mathrm{~N}$ & $0,99^{* *}$ \\
$\mathrm{Zn}$ & $101,06+1,421 \mathrm{~N}$ & $0,99^{* *}$ & $117,724+1,89 \mathrm{~N}$ & $0,99^{* *}$ \\
$\mathrm{Mn}$ & $474,03+4,328 \mathrm{~N}$ & $0,99^{* *}$ & $493,72+6,73 \mathrm{~N}$ & $0,98^{* *}$ \\
$\mathrm{Fe}$ & $919,3+4,96 \mathrm{~N}$ & $0,92^{* *}$ & $852,638+7,19 \mathrm{~N}$ & $0,94^{* *}$ \\
$\mathrm{MS}$ & $5421,5+67,4 \mathrm{~N}$ & $0,99^{* *}$ & $4187,5+203,48 \mathrm{~N}-0,65213 \mathrm{~N}^{2}$ & $0,97^{* *}$ \\
\hline
\end{tabular}

MS = matéria seca, extração de N, P, K, Ca, Mg, S, em kg ha-1 e de Cu, Zn, Mn, Fe, em g ha-1.

${ }^{*}$ ou ${ }^{* *}=$ significância do teste $\mathrm{F}$ no nível de 5 e $1 \%$.

$M S=$ dry matter, extraction of $N, P, K, C a, M g, S$, in $\mathrm{kg} \mathrm{ha}^{-1}$ and of $\mathrm{Cu}, \mathrm{Zn}, \mathrm{Mn}$ and $\mathrm{Fe}$, in $\mathrm{g} \mathrm{ha}^{-1}$.

${ }^{*}$ or ${ }^{* *}=$ significance of F-test at the level of 5 and $1 \%$.

R. Bras. Zootec., v.33, n.1, p.68-78, 2004 
São Paulo, para as gramíneas do grupo I, no qual o capim-coastcross se enquadra (Werner et al., 1996), são menores que as obtidas neste trabalho, por destinarem-se ao manejo de pastagem para sistemas extensivos ou semi-intensivos de produção de bovinos.

\section{Conclusões}

Os teores dos macro e micronutrientes na parte aérea das plantas de capim-coastcross, com exceção do $\mathrm{P}$ e Fe, em geral, aumentaram com as doses de $\mathrm{N}$ aplicadas.

Tabela 5 - Extração e recuperação aparente de $\mathrm{N}$ pela parte aérea do capim-coastcross, em cinco períodos de cortes consecutivos

Table 5 - Extraction and apparent recovery of $N$ by the above ground part of coastcross grass, in five consecutives cutting periods

\begin{tabular}{|c|c|c|c|c|c|c|c|c|c|c|c|c|}
\hline \multirow[t]{2}{*}{$\begin{array}{l}\text { Doses de } \mathrm{N} \\
N \text { rates }\end{array}$} & & 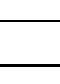 & \multicolumn{2}{|c|}{$\begin{array}{c}\text { Extração de } \mathrm{N} \\
N \text { extraction }\end{array}$} & - & - & & 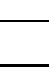 & \multicolumn{2}{|c|}{$\begin{array}{c}\text { Recuperação de } \mathrm{N} \\
N \text { recovery }\end{array}$} & \multirow[b]{2}{*}{$5 \underline{0}$} & \multirow[b]{2}{*}{ me. } \\
\hline & $1 \underline{\mathrm{o}}$ & $2 \underline{\underline{o}}$ & $3 \underline{0}$ & $4 \underline{\mathrm{O}}$ & $5 \underline{0}$ & me. & $1 \underline{\mathrm{o}}$ & $2 \underline{0}$ & $3 \underline{0}$ & $4 \underline{\mathrm{o}}$ & & \\
\hline
\end{tabular}

\begin{tabular}{|c|c|c|c|c|c|c|c|c|c|c|c|c|}
\hline \multicolumn{13}{|c|}{$\begin{array}{l}\text { Uréia } \\
\text { Urea }\end{array}$} \\
\hline 0 & 1 & 9 & 10 & 37 & 12 & 14 & - & - & - & - & - & - \\
\hline 25 & 2 & 22 & 24 & 54 & 26 & 26 & 3 & 50 & 55 & 57 & 60 & 45 \\
\hline 50 & 4 & 54 & 29 & 76 & 40 & 41 & 6 & 88 & 36 & 74 & 56 & 52 \\
\hline 100 & 13 & 86 & 48 & 105 & 67 & 64 & 11 & 74 & 36 & 59 & 52 & 46 \\
\hline 200 & 31 & 146 & 65 & 141 & 93 & 95 & 15 & 65 & 25 & 41 & 37 & 37 \\
\hline Média & & & & & & & & & & & & \\
\hline Mean & 10 & 63 & 35 & 82 & 48 & 48 & 9 & 69 & 38 & 58 & 51 & 45 \\
\hline Doses & & & & & & & & & & & & \\
\hline Rates & & & & & & $\mathrm{Q}^{* *}$ & & & & & & $\mathrm{~L}^{*}$ \\
\hline $\mathrm{R}^{2}$ & & & & & & 0,98 & & & & & & 0,37 \\
\hline \multicolumn{13}{|c|}{$\begin{array}{l}\text { Nitrato de amônio } \\
\text { Ammonium nitrate }\end{array}$} \\
\hline 0 & 1 & 10 & 8 & 39 & 12 & 14 & - & - & - & - & - & - \\
\hline 25 & 3 & 32 & 25 & 64 & 33 & 32 & 7 & 87 & 65 & 92 & 87 & 67 \\
\hline 50 & 13 & 63 & 48 & 85 & 60 & 54 & 24 & 100 & 79 & 77 & 96 & 75 \\
\hline 100 & 26 & 108 & 82 & 136 & 84 & 89 & 34 & 94 & 70 & 77 & 66 & 68 \\
\hline 200 & 118 & 142 & 78 & 147 & 89 & 115 & 58 & 61 & 32 & 39 & 35 & 45 \\
\hline $\begin{array}{l}\text { Média } \\
\text { Mean }\end{array}$ & 34 & 71 & 49 & 94 & 56 & 61 & 31 & 86 & 65 & 71 & 71 & 65 \\
\hline \multicolumn{13}{|l|}{ Doses } \\
\hline Rates & & & & & & $\mathrm{Q}^{* *}$ & & & & & & $\mathrm{~L}^{* *}$ \\
\hline $\mathrm{R}^{2}$ & & & & & & 0,98 & & & & & & 0,58 \\
\hline
\end{tabular}

Teste $\mathrm{F}$

F test

Fontes de N

$N$ sources

ext.= extração de $\mathrm{N}$ pela matéria seca, em $\mathrm{kg} \mathrm{ha}^{-1}$; rec. $=\mathrm{N}$ recuperado do adubo, em \%; me. $=$ média

${ }^{*}$ ou ${ }^{* *}=$ significância do teste $\mathrm{F}$ em nível de 5 e $1 \%$. Para doses, apresentada a curva de melhor ajuste $(\mathrm{L}=\mathrm{Linear}$ simples ou $\mathrm{Q}=$ Quadrática) e o valor do $\mathrm{R}^{2}$

extr. $=N$ extraction by dry matter, in $\mathrm{kg} \mathrm{ha}^{-1} ;$ rec. $=$ recovery fertilizer of fertilizer, in \%; me. = mean.

${ }^{*}$ or $^{* *}=$ significance of F-test at the level of 5 and $1 \%$. For rates, it showed the best adjusted curve type ( $L=L$ inear or $Q=Q$ Quadratic) with the $R^{2}$ value. 
Altas produções de forragem de capimcoastcross extraem elevadas quantidades de nutrientes da área, principalmente de $\mathrm{N}$ e $\mathrm{K}$.

A recuperação aparente do $\mathrm{N}$ pelo capimcoastcross é alta e influenciada pelas fontes e doses de N.

\section{Literatura Citada}

ALMEIDA, C.R.; MONTEIRO, F.A. Respostas de Cynodon dactylon cv. coastcross-1 a níveis de nitrogênio em solução nutritiva. In: CONGRESSO BRASILEIRO DA CIÊNCIA DO SOLO, 25., 1995, Viçosa, MG. Anais... Viçosa: Universidade Federal de Viçosa, 1995. v.2, p.743-744.

ARNON, I. Mineral nutrition of maize. Bern: International Potash Institute, 1975. 452p.

BODDEY, R.M.; RAO, I.M.; THOMAS, R.J. Nutrient cycling and environmental impact of Brachiaria pastures. In: WILES, J.W.; MAASS, B.L.; VALLE, C.B. (Eds.). Brachiaria: biology, agronomy and improvement. Cali: CIAT, 1996. p.72-86.

BRETELER, H. A comparison between ammonium and nitrate nutrition of young sugar-beet plants grown in nutrient solutions at constant acidity. 1. Production of dry matter, ionic balance and chemical composition. Netherlands Journal Agricultural Science, v.21, p.227-244, 1973.

BRUNET, E.; ASPIOLEA, J.L.; AVILA, A. et al. Respuesta de cuatro gramineas a la fertilización nitrogenada bajo condiciones de secano. 3. Exportacion y efectos sobre el suelo. Ciencia y Tecnica en la Agricultura, Suelos y Agroquímica, v.11, n.3, p.25-34, 1998a.

BRUNET, E.; ASPIOLEA, J.L.; RIOS, C. et al. Respuesta de cuatro gramineas a la fertilización nitrogenada bajo condiciones de secano. 2. Composición quimica. Ciencia y Tecnica en la Agricultura, Suelos y Agroquímica, v.11, n.3, p.17-24, 1988 b.

CORRÊA, L.A.; CANTARELLA, H.; PRIMAVESI, A.C. et al. Dry matter production response of Coastcross (Cynodon dactylon (L.) Pears) to sources and rates of nitrogen. In: INTERNATIONAL GRASSLAND CONGRESS, 19., 2001, Piracicaba. Proceedings... Piracicaba: Fundação de Estudos Agrários Luiz de Queiroz, 2001. p.193-194.

CORSI, M. Adubação nitrogenada das pastagens. In: SIMPÓSIO SOBRE MANEJO DE PASTAGENS, 2., 1975, Piracicaba. Anais... Piracicaba: Fundação de Estudos Agrários Luiz de Queiroz, 1975. p.112-142.

CORSI, M. Pastagem de alta produtividade. In: SIMPÓSIO SOBRE MANEJO DE PASTAGENS, 8., 1986, Piracicaba. Anais... Piracicaba: Fundação de Estudos Agrários Luiz de Queiroz, 1986. p.499-512.

CORSI, M. Adubação nitrogenada em pastagens. In: PEIXOTO, A.M.; MOURA, J.C.; FARIA, V.P. (Eds.). Pastagens: fundamentos da exploração racional. Piracicaba: Fundação de Estudos Agrários Luiz de Queiroz, 1994. p.121-155.

CORSI, M.; MARTHA JR., G.B. Manutenção da fertilidade do solos em sistemas intensivos de pastejo rotacionado. In: SIMPÓSIO SOBRE MANEJO DA PASTAGEM, 14., 1997, Piracicaba. Anais... Piracicaba: Fundação de Estudos Agrários Luiz de Queiroz, 1997. p.161-192.

COTO, G.; HERRERA, R.S.; CRUZ, R. et al. Effect of season and $\mathrm{N}$ fertilization on the quality and solubility of protein of bermudagrass. Cuban Journal of Agricultural Science, v.24, p.117-122, 1990.

COUTINHO, E.L.M.; RODRIGUES, L.R.A.; CONSOLINI, F. et al. Efeitos da adubação nitrogenada e potássica na produção de matéria seca e na composição mineral do capim Coastcross irrigado. In: REUNIÃO ANUAL DA SOCIEDADE BRASILEIRA DE ZOOTECNIA, 38., 2001, Piracicaba. Anais... Piracicaba: Fundação de Estudos Agrários Luiz de Queiroz, 2001. p.299-301.

FERNANDES, M.S.; ROSSIELO, R.O.P. Aspectos do metabolismo e utilização do nitrogênio em gramíneas tropicais. In: MATTOS, H.B.; WERNER, J.C.; YAMADA, T. et al. (Ed.). Calagem e adubação de pastagens. Piracicaba: Associação Brasileira para Pesquisa da Potassa e do Fosfato, 1986. p.93-123.

FERNANDEZ, D.; PARETAS, J.J.; SOCA, M. et al. Efecto de diferentes niveles de $\mathrm{N}$ en la produccion de cinco gramineas tropicales en suelo pardo tropical. Ciencia y Técnica en la Agricultura, Pastos y Forrajes, v.9, n.2, p.27-49, 1986.

FONSECA, I.; FLORES, E.; PACHECO, O. Fertilization nitrogenda en bermuda cruzada $\mathrm{n} .1$ (Cynodon dactylon $\mathrm{x}$ Cynodon nlemfuensis) en suelos pardos grisaceos. Ciencia y Tecnica en la Agricultura, Suelos y Agroquímica, v.7, n.3, p.55-62, 1984.

GATES, C.E. A user's guide to misanalyzing planned experiments. Hort Science, v.26, n.10, p.1262-1265, 1991.

GOMES, J.F.; SIEWERDT, L.; SILVEIRA JR., P. Avaliação da produtividade e economicidade do feno de capim pangola (Digitaria decumbens Stent) fertilizado com nitrogênio. Revista da Sociedade Brasileira de Zootecnia, v.16, n.6, p.491-499, 1987.

GOMIDE, J.A.; LEÃO, M.I.; OBEID, J.A. et al. Avaliação de pastagens de capim-colonião e capim-jaraguá. Revista da Sociedade Brasileira de Zootecnia, v.13, n.11, p.1-9, 1984.

MALAVOLTA, E. Elementos de nutrição mineral de plantas. São Paulo: Editora Agronômica Ceres, 1980. 251p.

MALAVOLTA, E.; VITTI, G.C.; OLIVEIRA, S.A. Avaliação do estado nutricional das plantas: princípios e aplicações. Piracicaba: POTAFOS, 1989. 201p.

MARASCHIN, G.E. Manejo de plantas forrageiras dos gêneros Digitaria, Cynodon e Chloris. In: SIMPÓSIO SOBRE MANEJO DE PASTAGENS, 9., 1988, Piracicaba. Anais... Piracicaba: Fundação de Estudos Agrários Luiz de Queiroz, 1988. p.109-139.

MESA, A.R.; MENDONZA, F.; AVILA, V. Rendimiento, composicion quimica y niveles criticos de potasio en cuatro gramineas tropicales. Pastos y Forrajes, v.12, n.1, p.43-51. 1989.

MILLER, G.L. Potassium application reduces calcium and magnesium levels in bermudagrass leaf tissue and soil. HortScience, v.34, p.2, p.265-268. 1999.

MONTEIRO, F.A. Adubação em áreas de Cynodon para pastejo e conservação. In: SIMPÓSIO SOBRE MANEJO DA PASTAGEM, 15., 1998, Piracicaba. Anais... Piracicaba: Fundação de Estudos Agrários Luiz de Queiroz, 1998. p.173-202.

MOTT, G.O. Nutrient recycling in pastures. In: MAYS, D.A. (Ed.). Forage fertilization. Madison: Soil Science Society of America, 1974. p.323-339.

OLSEN, F.J. Effect of large application of nitrogen fertilizer on the productiviy and protein content of four tropical grasses in Uganda. Tropical Agriculture, v.49, n.3, p.251-260, 1972 . 
PRIMAVESI, O.; CORREAA, L.A.; PRIMAVESI, A.C. et al. Adubação com uréia em pastagem rotacionada de Cynodon dactylon cv. Coastcross: Eficiência e perdas. São Carlos: Embrapa Pecuária Sudeste, 2001. 42p.(Circular Técnica, 30)

PRIMAVESI, A.C.; CORREAA, L.A.; PRIMAVESI, O. et al. Eficiência nutricional de duas fontes de nitrogênio na produção de matéria seca de Coastcross. In: REUNIÃO ANUAL DA SOCIEDADE BRASILEIRA DE ZOOTECNIA, 37., 2000, Viçosa, MG. Anais... São Paulo: Gmosis, 2000, 11 par. CD-ROM. Forragicultura. FOR-0764.

QUINN, L.R.; MOTT, G.O.; BISCHOFF, W.V.A. et al. Produção de carne em bovinos submetidos a pastoreio em seis gramíneas tropicais. Boletim da Industria Animal, v.20, p.250-279, 1962.

STATISTICAL ANALYSES SYSTEM - SAS. SAS/STAT User's guide: statistics. Versão 6.4. Cary: 1993. 1686p.

SILVA, S.C. Condições edafoclimáticas para a produção de Panicum sp. In: SIMPÓSIO SOBRE MANEJO DA PASTAGEM, 12., 1995, Piracicaba. Anais... Piracicaba: Fundação de Estudos Agrários Luiz de Queiroz, 1995. p.129-146.

TERMAN, G.L. Volatization losses of nitrogen as ammonia from surface-applied fertilizers, organic amendments, and crop residues. Advance Agronomy, v.31, p.189-223, 1979.

USHERWOOD, N.R. Interação do potássio com outros íons. In: YAMADA, T.; IGUE, K.; MUZILLI, O.; USHERWOOD, N. R. (Eds.). Potássio na agricultura brasileira. Piracicaba: Instituto da Potassa \& Fosfato, 1982. p.227-247.
VICENTE-CHANDLER, J.; SILVA, S.; FIGARELLA, J. The effect of nitrogen fertilization and frequency of cutting on the yield and composition of three tropical grasses. Agronomy Journal, v.51, n.4, p.202-206, 1959.

WERNER, J.C.; PEDREIRA, J.V.S; CAIELE, E.L. Estudo de parcelamento e níveis de adubação nitrogenada com capim pangola (Digitaria decumbens Stent). Boletim da Industria Animal, v.24, p.147-151, 1967.

WERNER, J.C.; PAULINO, V.T.; CANTARELLA, H. et al. Forrageiras. In: Van RAIJ, B.; CANTARELLA, H.; QUAGGIO, J.A. et al. (Eds.). Recomendações de adubação e calagem para o Estado de São Paulo. Campinas: Instituto Agronômico, 1996. p.263-273 (Boletim Técnico, 100)

WHITEHEAD, D.C. Volatilization of ammonia. In: WHITEHEAD, D.C. (Ed.). Grassland nitrogen. Wallingford: CAB International, 1995. p.152-179.

WILKINSON, S.R.; LOWREY, R.W. Cycling of mineral nutrients in pasture ecosystems. In: BUTLER, G.W; BAILEY, R.W. (Eds.). Chemistry and biochemistry of herbage. London: Academic Press, 1973. p.248-315.

Recebido em: 08/03/02 Aceito em: 01/08/03 